\title{
Modelling and Simulation of Fermentation Product Purification for Local Vinegar using Batch Distillation
}

\author{
Faezah Bt Bakar \\ University Malaysia Pahang, Kuantan, Malaysia \\ ieyjah89_rose@yahoo.com.my
}

\begin{abstract}
Batch distillation has important due to its flexibility and capability to produce high purity product. The simulation of batch distillation columns during steady state operations is a very challenging modelling problem because of the complex dynamic behaviour. In order to verify this issue, simulation of this batch distillation column is to be performed by using computer aided design software and mathematical model .This study is required to model and simulate of fermentation product purification using batch distillation. This research was done by using graphical method and simulating by using MATLAB software that simple model had been presented. The results from these simulations were used as a basis to validate the results obtained (by others) experimentally. As conclusion, distillate and bottoms composition for ethanol drop gradually over time by using graphical method and the trend from simulation showed that the distillate and bottoms composition for ethanol increase and decrease over the time respectively. The declining trend was due to the unsteady state nature of batch distillation, where the lighter component at the bottoms will deplete over time.
\end{abstract}

Keywords: MATLAB®, graphical method, batch distillation, simulation, modeling

\section{Introduction}

Batch distillation process is an important separation technique for many centuries that used in many areas of pharmaceutical and especially in chemical industries. It uses for separating or purifying liquid mixtures and waste removal in chemical process industries. Therefore, it has common issues for the researchers in order to design alternative and suitable column configurations, to develop of mathematical models in line with the development of numerical methods and to use of artificial software networks in dynamic modelling, optimisation and control for local vinegar.

Simulation is usually the first step to conduct feasibility study of a design before it can be implement into a big industrial scale plant. Not only feasibility study, simulation give a better understanding of a process, approximation of the cost to setup and potential challenges that the process may face upon setting up the design to industrial scale.

\section{Modeling Batch Distillation Column Configurations}

According to Mujtaba [1] and Diweker [2], batch distillation column can be operating in various configurations. There are two types of configuration which are conventional column configuration and unconventional column configuration. But, the alternative configuration that has found more advantages is unconventional column distillation. Unconventional configuration consists of inverted batch distillation, middle vessel batch distillation column, multi vessel batch distillation column and continuous column. Both writers agree that it is multi vessel batch distillation column of configuration to obtain purer product at the of a total reflux operation.

\section{Modeling and Simulation}

According to Mujtaba [1] simulation is the actual operation which consists of simulation of start-up period and simulation of product period. Many research has been done by simulating the operation of convectional column including by Mujtaba [1], Diweker [2] and Ronnie [3]. In simulation, it is important to develop a model before run the simulation. The model should consist of mass and energy balance, hydraulic model, physical properties and etc. 
In modelling, it requires to know whether and how to include energy balance, hydraulic model, accurate physical properties to simulate the actual operation batch distillation. It found that the model had to be simplified first because of size and complexity of the problem, capabilities of computer, and availability of suitable numerical methods to integrate the model equations, gain in accuracy in the prediction of real operation [1].

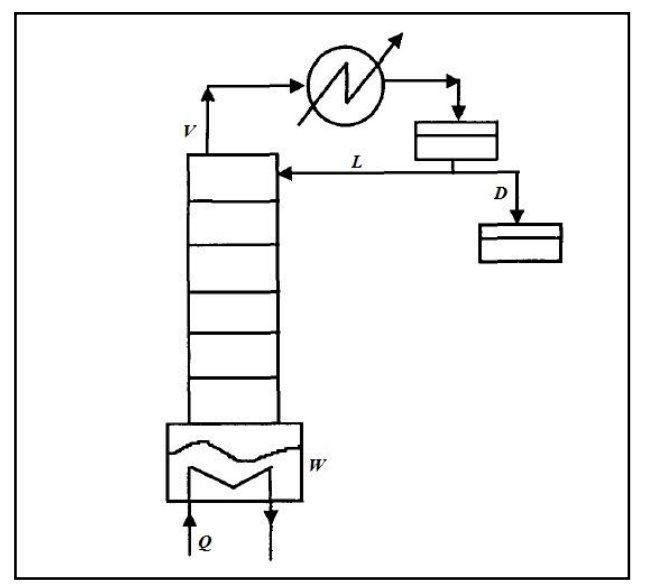

Figure 1. Conventional Batch Distillation Column

\section{Computer Software Simulation}

Computer software simulation is done by using commercial software (MATLAB ®) and validated using graphical method. MATLAB provides functions for performing mathematical operations and analyzing data. The conventional batch distillation that used in this research is simple batch distillation (Rayleigh distillation). In this model, the vapour is removed from the still during a particular time interval and is condensed in the condenser. The more volatile components are richer in the vapour than in the liquid remaining in the still [2].

\section{Mathematical Model Equations}

A simple batch distillation model of the batch distillation operation involves solving several differential equations. The first detailed analysis of batch distillation represented by Mujtaba [1]. He points the equations for the condenser are presented. Then, the equation for the accumulator, followed by equations for the plates in the column and the reboiler are presented. The trays are counted from the top to the bottom. Before running simulation, the boil-up rate of batch distillation operation needs to be calculated.

$$
H e=A\left(1-\frac{T}{T C}\right)^{n}
$$

Where $H, \mathrm{Tc}, \mathrm{T}, \mathrm{A}$ and $\mathrm{n}$ are temperature, enthalpy of vaporisation, critical temperature, and regression coefficient for chemical compound respectively. Once the latent heat of vaporisation was found and together with the heat input of the system, boil-up rate of the system can be calculated by using:

$$
\mathrm{Q}=\left(x_{\mathrm{e}} H_{\mathrm{e}}+x_{\mathrm{w}} H_{\mathrm{w}}\right) \cdot V
$$

Where,

$\mathrm{Q}=$ heat input, $\mathrm{KW}$

$x_{e}=$ mole fraction of ethanol

$x_{w}=$ mole fraction of water

$H_{\mathrm{e}}=$ enthalpy of vaporisation of ethanol, $\mathrm{kJ} / \mathrm{mol}$

$H_{w}=$ enthalpy of vaporisation of water, $\mathrm{kJ} / \mathrm{kmol}$

$V=$ vapour boil-up rate, $\mathrm{kmol} / \mathrm{s}$

a. Rayleigh Model with Constant Reflux

Batch distillation under constant reflux can be analysed mathematically by using Rayleigh equation.

Originally, a charge of $L_{o}$ of moles of components A and B with composition of $x_{o}$ mole fraction of A is placed in the still. At any given time, there are $L$ mole of liquid left in the still with composition $x$ and the composition of the vapour leaving in equilibrium is $y$. A differential amount $d L$ is vaporized. Thus, 


$$
-d L=d x L
$$

The differential material balance for lighter component can be written as:

$$
L d x+x d L=y d L
$$

Rearranging and integrating,

$$
\int_{L t}^{L o} \frac{d L}{L}=\ln \frac{L o}{L}=\int_{x t}^{x o} \frac{d x}{(y-x)}
$$

Where,

$L o=$ initial charge, $\mathrm{kmol}$

$L t=$ total holdup at bottom at any time, $\mathrm{kmol}$

$x o=$ initial bottom composition of lighter component

$x t=$ bottom composition of lighter component at any time

The average composition of total material distilled, $y_{a v}$ can be obtained by material balance:

$$
L_{o} X_{o}=L_{t} X_{t}+\left(L_{o}-L_{t}\right) y_{a v}
$$

The bottoms holdup at any time can be found by using

$$
L t=L o-\frac{V t}{R+1}
$$

Where:

$\mathrm{Lt}=$ total holdup at bottom at any time, $\mathrm{kmol}$

Lo = initial charge, kmol

$V=$ boil rate, $\mathrm{kmol} / \mathrm{s}$

$R=$ reflux ratio

\section{b. Simple Model}

The component balance for the holdup tank is:

$$
\frac{d x l i}{d t}=\frac{V}{H C}(y 2 i-x l i)
$$

The reflux ratio is defined as:

$$
\mathrm{L}=\mathrm{rV}
$$

The total mass balance for reboiler is written as:

$$
\frac{d H N}{d t}=L-V
$$

Then, the component mass balance is

$$
\mathrm{H}_{\mathrm{N}} \frac{d x i}{d t}=L(x-1, i-x, i)-V(y-x, i)(11)
$$

\section{Results and Discussion}

\section{Graphical Method}

By using the initial condition $\mathrm{t}=10$ minutes as example the initial total hold up at the bottoms that calculated is $0.3631 \mathrm{kmol}$ with the ethanol and water mole fraction of $0.2357 \mathrm{kmol}$ and $0.7643 \mathrm{kmol}$ respectively. Value of $y$ and $x$ were calculated by using equation (5) and equation (6). The integration of equation (6) can be done by calculating values of $f(x)=1 /(y-x)$ and numerically or graphically integration equation (5) between $x_{t}$ and $x_{0}$. The area under the curve will give value of $\ln \left(L_{1} / L_{2}\right)$ and to avoid graphically integration, an equation to fit the curve was obtained by using Microsoft Excel as shown in the Figure 2. The unknown is $x_{1}$, the composition of liquid $L_{2}$ at the end of the differential distillation. To solve this numerical integration, the equilibrium data can be fitted to a polynomial function as shown in Figure 2. 


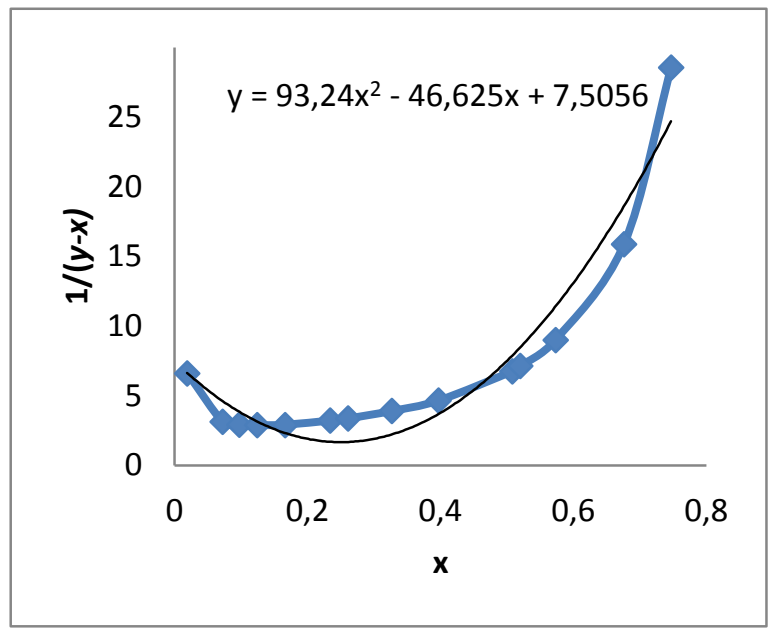

Figure 2. Numerical Integration for Ethanol-Water

Then, polynomial equation from the graph was used to find the value of at certain using equation 5 . Thus, the average composition of total material distilled, $y_{a v}$, can be obtained by equation (6). Calculations at time 20,40, 60, 80 and 100 minutes are done based on the same method as above. The results from the calculation are tabulated in the Table 1.

Table 1. Composition of Distillate and Bottom at Constant Reflux from Graphical Method

\begin{tabular}{|c|c|c|c|c|}
\hline \multirow{2}{*}{$\begin{array}{c}\text { Time,t } \\
\text { (minutes) }\end{array}$} & \multicolumn{2}{|c|}{ Mole Fraction at distillate } & \multicolumn{2}{c|}{ Mole Fraction at bottom } \\
\cline { 2 - 5 } & Ethanol & Water & Ethanol & Water \\
\hline 0 & 0 & 0 & 0.2357 & 0.7643 \\
\hline 10 & 0.860751 & 0.139249 & 0.2267 & 0.7733 \\
\hline 20 & 0.805029623 & 0.194970377 & 0.2184 & 0.7816 \\
\hline 40 & 0.78010242 & 0.21989758 & 0.2009 & 0.7991 \\
\hline 60 & 0.752164099 & 0.247835901 & 0.1842 & 0.8158 \\
\hline 80 & 0.721925082 & 0.278074918 & 0.1686 & 0.8314 \\
\hline 100 & 0.692557599 & 0.307442401 & 0.1539 & 0.8461 \\
\hline
\end{tabular}

The profile of mole fraction at distillate and bottom were plotted as shown in Figure 3 and Figure 4.

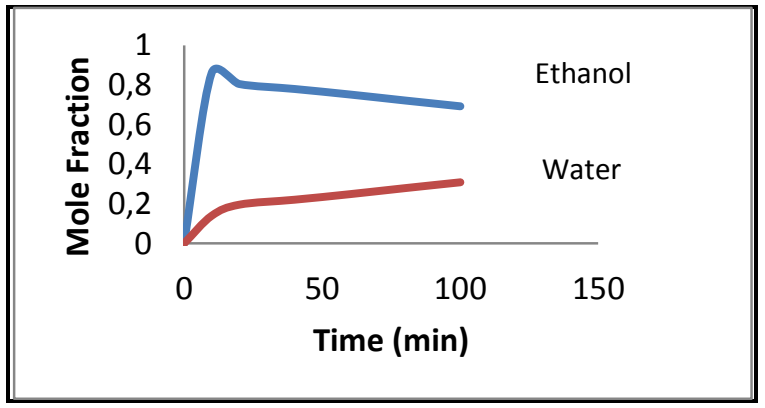

Figure 3. Theoretical dynamic response of mole fraction of component in the condenser 


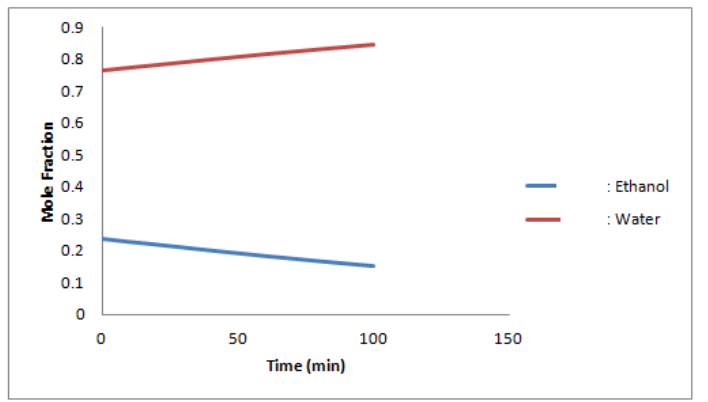

Figure 4. Theoretical dynamic response of mole fraction of component in the reboiler

\section{Comparison between Simulation of the Model by Using MATLAB ${ }^{\circledR}$ Software and Graphical Method}

During the simulation, the reflux ratio was set to be constant $(\mathrm{R}=4)$. Model equations of equation 8 and 11 were solved by an explicit Euler method and it was possible to discuss simulation parameters and their influence on composition and process dynamics.

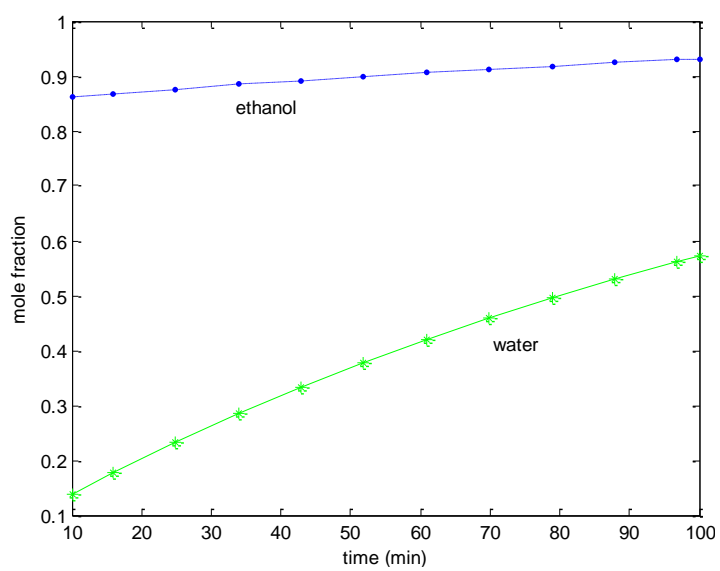

Figure 5. Theoretical dynamic responses of mole fractions of components in the condenser.

Figure 5 shows the dynamics responses of mole fractions of components in the segment of the condenser. As can be seen from Figure 5, the dynamics response of the mole fraction of ethanol and water were increase as time increase. At condenser, mole fraction of ethanol was higher than mole fraction of water at time of 10 minutes. It is because boiling point of ethanol is lower than water, thus ethanol vaporised first. But from graphical method and experiment, it showed that mole fraction of ethanol will decreased after 30 minutes. In contrast, by simulation the mole fraction of ethanol continuously increasing without dropped. It recognized that some assumption made in simulation model is error or not valid to the modelling.

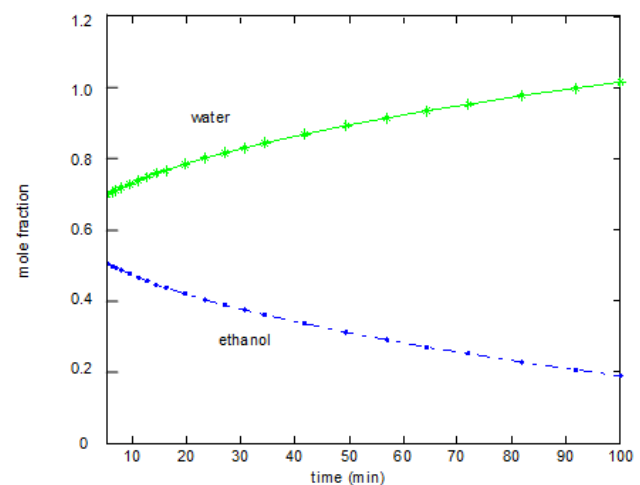

Figure 6. Theoretical Dynamic Responses of Mole Fractions of Components in the Reboiler (Bottom).

Considering Figure 6, it was discovered that the mole fraction of ethanol was low in the reboiler compared to the water in the condenser. This is because ethanol being more volatile than water. Meanwhile 
the mole fraction of water was increasing over the time. At bottom, the mole fraction for both was validated from graphical method under difference mole fraction.

\section{Experimental Results by Others}

Experiment results which previously done by others was extracted to obtain the composition of ethanol at the condenser.

\section{Table 2. Experiment Results at Constant Reflux}

\begin{tabular}{|c|c|c|}
\hline \multirow{2}{*}{$\begin{array}{c}\text { Time } \\
(\mathrm{min})\end{array}$} & \multicolumn{2}{|c|}{ Mole Fraction } \\
\cline { 2 - 3 } & Ethanol & Water \\
\hline 0 & 0 & 0 \\
\hline 5 & 0.32434 & 0.675657 \\
\hline 10 & 0.8528 & 0.147201 \\
\hline 20 & 0.83392 & 0.166076 \\
\hline 30 & 0.76873 & 0.231272 \\
\hline 40 & 0.90976 & 0.090245 \\
\hline 60 & 0.92858 & 0.07142 \\
\hline 90 & 0.91371 & 0.086294 \\
\hline 120 & 0.85349 & 0.146509 \\
\hline
\end{tabular}

\section{Conclusion}

As conclusion, distillate and bottoms composition for ethanol drop gradually over time by using graphical method. The declining trend was due to the unsteady state nature of batch distillation, where the lighter component at the bottoms will deplete over time. The trend from simulation showed that the distillate and bottoms composition for ethanol increase and decrease over the time respectively. As using computer software simulation, it able to integrate the model equations for fermentation product purification based on suitable numerical methods and it also gain the understanding due to simulation.

The result obtained from this study has shown there were quite good agreements between the distillate and bottom compositions estimated by graphical method and experimental study. Their percentage absolute errors for ethanol distillate and ethanol bottom were $14.7 \%$ and $124.5 \%$ respectively. It was not high that was not set as the criterion for validity of the model equations. Therefore, the experiment results have been found not accurate results in representing the batch distillation. Responding to this error, troubleshooting was carried out on the existing column and faulty instruments were identified. The reflux splitter was found to be faulty and was not functioning properly, causing incorrect split of reflux and distillate.

For future project for this research is controlling the reflux ratio for binary mixture batch distillation to obtain constant distillate composition that can be carried out using graphical method

\section{Acknowledgement}

I am heartily thankful to my supervisor in this project, Dr. Anwaruddin Hisyam, for his endless guidance, advises, and her patience throughout this project. I would like to express my greatest gratitude to my family member especially my parent for their endless financial support throughout my study in University of Malaysia Pahang (UMP). Thanks to my course mates who has helped me out on this project. Their encouragement and helpfulness is much appreciated and never would I forget.

\section{Nomenclature}

$H$ : enthalpy of vaporisation

$[\mathrm{KJ} / \mathrm{mol}]$

Tc : critical temperature

[K]

$\mathrm{T}$ : temperature

$[\mathrm{K}]$

A and n: regression coefficient for chemical compound respectively

Q : heat input

[KW]

$x_{e}$ : mole fraction of ethanol [mole]

$x_{w}:$ mole fraction of water [mole]

$H_{\mathrm{e}}$ : enthalpy of vaporisation of ethanol $[\mathrm{KJ} / \mathrm{mol}]$

$H_{w}$ : enthalpy of vaporisation of water $\quad[\mathrm{KJ} / \mathrm{mol}]$

$V$ : vapour boil-up rate

$[\mathrm{kmol} / \mathrm{s}]$ 


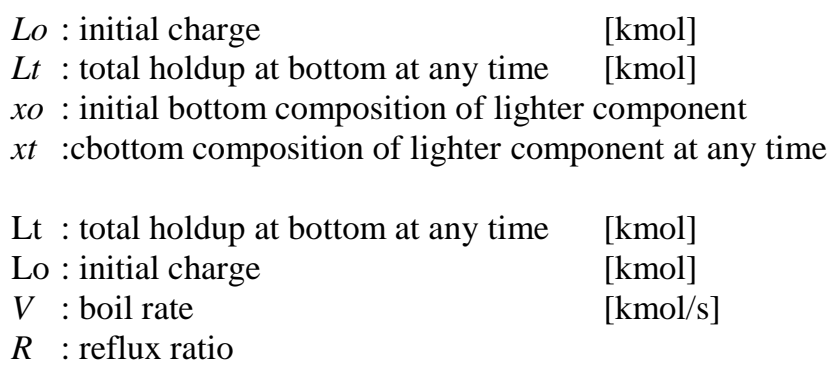

$R$ : reflux ratio

\section{References}

[1] Mujtaba I.M. (2004). Batch Distillation Design and Operation.Batch Distillation Design and Operation Series on Chemical Engineering,vol 3,Imperial College Press.

[2] Diwekar,U.M.(1996). Understanding Batch Distillation Process Principles with MultiBatch DS.Computer Application in Engineering Education, 4, 275-284.

[3] Ronnie, T.B.H (2011). Simulation of Batch Distillation Column: (Phd[Dissertation ]) Malaysia: University Tunku Abdul Rahman. 